\title{
Atomic structure and chemistry of complex oxide dispersoids in ferritic ODS steel clad tubes
}

\author{
Pradyumna Parida, ShyamKanta Sinha and Arup Dasgupta
}

Indira Gandhi Centre for Atomic Research, Kalpakkam, Tamil Nadu, India

The oxide dispersion strengthened (ODS) ferritic steels are one of the candidate structural materials for advanced fuel cladding application in future fast breeder reactor (FBR) fueled by U-Pu oxides. These steels possess exceptional high-temperature stability, neutron irradiation resistance, and creep strength as compared to currently used austenitic grade stainless steels due to reinforcement by hard and stable nanocrystalline ceramic oxides in the ferritic matrix. The dispersoids act as barriers to dislocation motion as well as serve as a site for radiation-induced point defect annihilation. The dispersoid size, structure, stoichiometry, and their distribution in the metallic matrix govern the physical and mechanical properties of the steel.In the ODS steels, Y2O3 (size 20-40 nm) are dispersed in the either Fe-9Cr-2W-0.2Ti$0.1 \mathrm{C}$ (9Cr ODS) or Fe-18Cr-2W-0.01C (18Cr ODS) steel matrix. Here, Ti is believed to refine the Y2O3 dispersoid by forming Y-Ti-O complex oxides whose typical size is in the range of $2-10 \mathrm{~nm}[1,2]$. However, the exact formation mechanism and crystallographic structure of the nano - dispersoids in these ferritic steels were barely understood. Based on the size and stoichiometry of the complex oxides, the oxide and matrix interface may vary from coherent to semi-coherent to incoherent.

In this study, an attempt has been made to study the atomic structure and chemistry of the Y-Ti-O complex oxide dispersoids and their interfaces in the 9Cr and 18Cr ODS ferritic steel clad tubes using the state-ofthe-art Titan Themis G2 300 TEM. TheTEM lamellas were prepared by the FIB technique and were analyzed. Figure 1( $\mathrm{a}$ and $\mathrm{b}$ ) represent the typical bright-field TEM micrograph of the 9Cr ODS and $18 \mathrm{Cr}$ ODS steel clad tubes respectively. Analysis of figure 1(a) shows that the carbides (indicated by the red arrow) are decorated along the prior austenite grain boundaries, whose size varies in the range of $50-150$ $\mathrm{nm}$, martensite laths were observed whose width varies in the range of $200-400 \mathrm{~nm}$. The dispersoids whose typical sizes of $\sim 5-10 \mathrm{~nm}$ were decorated uniformly in the ferritic martensitic matrix. Analysis of figure 1(b) reveals that the ferrite grains were elongated bamboo-like morphology and the width of these grains varies in the range of $200-500 \mathrm{~nm}$. Carbides were not observed in this 18Cr ODS steel, which may be attributed due to very low carbon content $(0.01 \mathrm{wt} . \%)$ in the steel, however, the dispersoid size and their distribution in the ferrite matrix are found to be uniform and similar to that of 9Cr ODS steel. In order to understand the dispersoid structure and stoichiometry in detail and their interfaces with the metal matrix in these steels, high-resolution microscopy using STEM-EDS technique as well as phasecontrast microscopy were used. Figure 2(a) represents the superimposed STEM-HAADF image and EDS maps of the same region of interest using Y-L $\alpha$, Ti-K $\alpha$, and O-K $\alpha$ X-rays obtained from 9Cr ODS steel Clad tube. The analysis of this micrograph reveals that the evolved complex oxides have two types of morphology, (1) core-shell and (2) biphase. Relatively finer dispersoid shows the core enriched with YTi-O and the shell with $\mathrm{TiO}$, whereas in other coarser dispersoids, which was formed by the combination of two phases placed adjacent to each other, one enriched with Y and other with Ti. Figure 2 (b) shows the phase-contrast micrograph of one of the Y-Ti-O dispersoids. The analysis of this micrograph reveals the core-shell type morphology, with the $\mathrm{d}$ - spacing measured to be $2.5 \AA$, and it matches with the Y2Ti2O7 (400). Similar observations were made with respect to the structure and chemistry of the dispersoids in the case of $18 \mathrm{Cr}$ ODS clad tubes. Size-dependent morphology, structure, and chemistry appear quite intriguing. In-depth atomic-scale chemistry of various types of dispersoids and their mechanism of formation are presently being studied in an aberration-corrected TEM. These results will be presented in detail during the conference. 

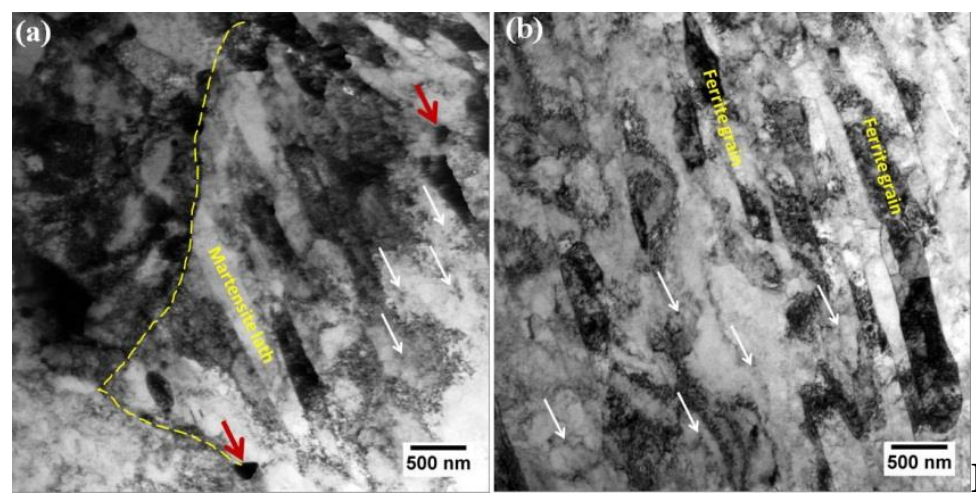
DS F/M steel clad tube showing martensite lath and decoration of the carbides (indicated by red arrow) along the prior austenite grain boundaries (indicated by the yellow dash line) and distribution of the dispersoids (indicated by white arrows) in ferritic martensitic matrix and (b) 18Cr ODS steel clad tube showing the elongated ferrite grains and also the dispersoids (indicated by white arrows) distribution in the ferrite matrix
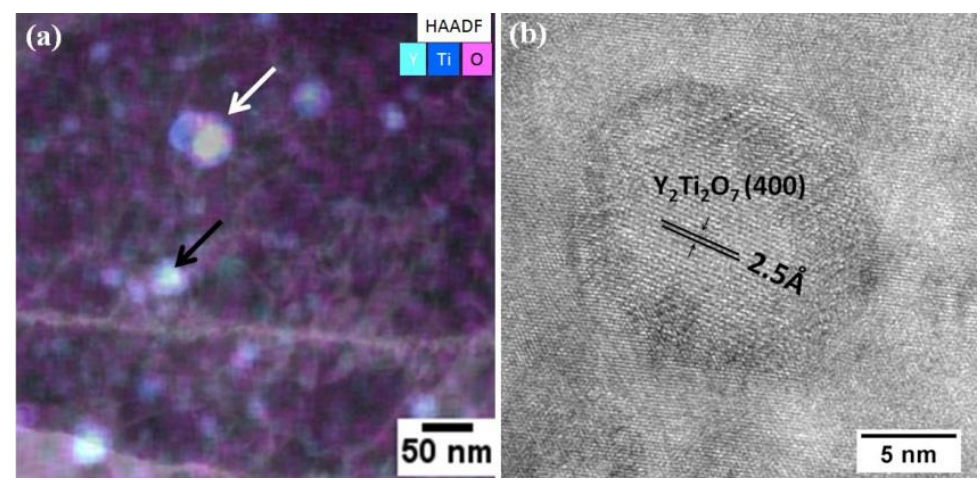

Figure 2. Figure 2. Structure and chemistry of the dispersoid in 9Cr ODS F/M steel clad tube (a) HAADF micrograph superimposed with the EDS elemental map using Y L $\alpha$, Ti K $\alpha$ and O K $\alpha$ X-rays (b) Phase-contrast micrograph of the dispersoid showing the core -shell type morphology

\section{References}

1. A. Dasgupta, R. Divakar, P.K. Parida, C. Ghosh, S. Saroja, E. Mohandas, M. Vijayalakshmi, T. Jayakumar, B. Raj, Electron Microscopy Studies on Oxide Dispersion Strengthened Steels, in: T. Böllinghaus, J. Lexow, T. Kishi, M. Kitagawa (Eds.), Materials Challenges and Testing for Supply of Energy and Resources, Springer Berlin Heidelberg, Berlin, Heidelberg, 2012, pp. 117-128.

2. G.R. Odette, On the status and prospects for nanostructured ferritic alloys for nuclear fission and fusion application with emphasis on the underlying science, Scripta Materialia 143 (2018) 142-148 